\title{
A Study on Applications of Housing Interior Design Elements according to the Sensibility Type
}

\section{감성유형에 따른 주거 실내디자인요소 적용방안}

\author{
박지민* \\ 박은 선** \\ Park, Ji-Min \\ Park, En-Sun
}

\begin{abstract}
The purpose of this study was to draw application elements of housing interior design according to user-oriented sensibility types. The sensibility evaluation experiments were conducted to target the general user 118 people using the sensibility evaluation tool for housing interior space. The results of the analysis were as: To produce the 'cozy' space, the colors and materials giving soft and natural feeling should be used. For the 'practical' space, type of ceiling and window that give the visually open feeling, the user-oriented furniture arrangement that allows using the space efficiently. For the 'cheerful' space, the simple and natural effects should be produced by using closed space that stable. For the 'traditional' space, the natural fishing material having rough texture should be used. For the 'unique' space, the space contained the dynamic feeling by the diagonal or vertical line and the graphic expression in the wall. For the 'congenial' emotional space, basic is the symmetric, stable and simple space. On the other hand, for the material, small size, natural texture or typical and soft materials should be used. For the 'sensuous' space, the dynamic and vertical sense of space should be expressed by the type of ceiling. The most important elements for the space of 'gorgeous' sensibility, is the color.
\end{abstract}

Keywords : Housing Interior Space, Sensibility Type, Design Attribute, Type I Quantification Theory 주 요 어 : 주거 실내공간, 감성유형, 디자인 속성, 수량화이론

\section{Introduction}

\section{Background}

Today, the principle of the added value for all the services and products is to provide the users with new experiences and much creative and high quality of emotional added value rather than the one-dimensional demands, which prioritizing quantitative values such as price, quality, etc. The creation of such emotional values has ultimate purpose of pursuing the quality of human life by evaluating, measuring, analyzing the demands and characteristics of the users scientifically and by applying those results substantially. The Kansei Engineering is focusing on the emotions and demands of the user for the environment, that is, the sensibility, and is to formulating the environmental design elements and the

*정회원(주저자, 교신저자), 미래공간문화연구소 전임연구원, 이학박사 **정회원, 미래공간문화연구소 소장, 이학박사

Corresponding Author: Ji-Min Park, Associate Researcher, Next Space \& Culture Lab, 77 Mokdongse-ro Yangchun-gu, Seoul, 158735, Korea. E-mail: minpj10@hanmail.net

이 연구는 박지민의 박사학위논문의 일부를 토대로 수정·보완한 연구임. human sensibility by converting the ambiguous expression on such environment into the detailed design through the collection of the technologies such as psychological evaluation, statistical analysis, artificial intelligence and graphics (Nagamachi, 1995). In the space design area, such as the increase in the interests in the role of sensibility and the effects of the sensibility on the user sis needed getting away from the supplier-oriented design method, which depended on the intuition of the designer. And the research of the sensibility design by Kansei Engineering Method is needed to develop the user-oriented space environment, which maximizes the satisfaction by identifying the sensibility, feeling, impression, etc.

In addition, the rational, accurate, much systematic Kansei Engineering approach differentiated from existing approach are not made in establishing the knowledge between the interior design element for housing space and the human sensibility. So there exist the limit in grafting the unclear and ambiguous qualitative sensibility data with the interior design elements. Among the diverse Kansei Engineering approaches, the statistical analysis plays the important role and is widely applied 
as the most systematic method for the Kansei Engineering. Particularly, the linear regression model in the Quantification theory is known as the most common tool to draw the relation between the human recognition and the product design elements (Schütte et al., 2004). Therefore, the limitation of existing research can be overcome using the much systematic user-oriented sensibility evaluation tool, and to identify the influences of the diverse and compound housing interior design on the human being, the researches through much systematic and specific Kansei Engineering approach are needed.

\section{Research purpose}

This study is intended to suggest the alternative for sustainable future housing interior space design responding to the sensibility of the user by drawing the interior design attributes by sensibility factors through the user's sensibility evaluation of the housing interior design. It is intended to draw the housing interior space design attribute accompanied with the user's sensibility by identifying the correlation between the housing interior design components and principle of construction, and the sensibility of the user according to the approach of quantification theory.

\section{Literature Review}

\section{Sensibility and form}

The first phase in the development of human perception lies in perceiving the form of the object or appearance. Appearance is the element to from the visual experience, and refers to the shape or form of the objects composed the structure. In the Gestalt psychology, a form is defined by the shape as an integrated whole having complete structure and wholeness. When perceiving the object, in the initial phase of perception, the brain classifies the object acquired by the eyes into simple patterns such as line, foreground and background, corner, contrast, etc. Such simple patterns allow the perceiver to verify the object based on the direction, color, etc. (Solso, 1996). The form is determined by the proportion of outlines, area, direction, etc. The form is changed differently by such elements, through which the expressions of sensibility changed differently. The sensibility that the user feels through the form are different such as sense of weight, sense of stability, exquisiteness, strength, weakness, freshness, lighting, motion, rhythmic sense, etc. (Lefebvre, 1991; Satoru, 1994)

\section{Sensibility and color}

Color is defined as that the color as a physical phenomenon is perceived through the eyes the sensory organ, or as a phenomenon indicated the experiential effects as same as such perceptual phenomenon. The color that we see and feel in our daily living is not perceived as one but exists interrelated with the color combination, area of use, etc. In the interrelation, it is perceived by the diverse phenomena of the color such as contrast, harmony, assimilation, etc. Color can be classified into objective and essential element that receives relatively little influences by the mental and cultural characteristics of the individual and the subjective element which receives lot of influences. These elements can be found in the relation between the sense of color and the sensibility. The sensibility about the explicitness, advancement / retreatment, expansion / contraction, sense of temperature, sense of weight, sense of dynamics, sense of solidness, and space sense are included in the objective element of color, and the mechanism of association of color, symbol, memory and signs are included in the subjective element (Junychi, 1994; Solso, 1996).

\section{Sensibility and materials}

Every material has basic property as a material and expresses its property in any manner. The texture refers to the superficial characteristics, and causes the sensuous reaction or tactile sensation from the memory even it cannot be felt actually. The dark and brightness in the diverse textures provide the visual lead allowing us to feel the texture. Since the texture can be expressed differently depending on how the individual feels and perceives the material, and specified as a material, the sensuous experiences for the material are important. Therefore, it is classified into tactile texture and visual texture by the perceptual patterns of the material (Neung, 1993).

\section{Sensibility and interior design attributes}

Saito, Munemoto and Matsushita (2005) conducted the sensibility evaluation from the traditional façade of the traditional buildings and proposed that there are significant differences between the formal element having influences on the traditional sensibility and the elements, which determined the combination depending on the majoring the architecture.

Takemura and Matsumoto (2008) extracted spatial element index to build the good conference room by extracting 
the important evaluation words for the office conference room and identifying the formal elements, which contribute to building good office space through the sensibility evaluation. One side of the opening space has the influences on the sensibility 'relax', but formal furniture gives the women tension. Open space and white color have the influences on the sensibility 'fresh', and open space, well-desiged interior and furnitures showed to improve creativity.

$\mathrm{Yu}$ (2008) identified the correlation between the words of image and the variables having influences on the evaluation of the words of image with the each category. The design attributes having significant influence on the sensibility 'dynamic' were straight, rough texture and blue, the influences by evaluation variables were represented as form, color and material in order. The design attributes having significant influence on the sensibility 'classic' were curve, smooth texture and yellow, the influences by evaluation variables were represented as material, form and color in order. The design attributes having significant influence on the sensibility 'light' were straight, rough texture and blue, the influences by evaluation variables were represented as color, form and material in order.

Park, Yoon and Park (2012) The purpose of this study is to grasp the correlation between user's sensibility and housing interior design attributes approach to Kansei Engineering. This experiment is carried out by the sensibility evaluation method of housing interior images with sensibility adjectives. The results of analysis are as follows: First, there are different the characteristics of Interior design attributes according to sensibility type. 'elegant' type is floor materials -wall materials, 'emotional' type is colors- form -color coordination, 'characteristic' type is form -wall material- floor materials, 'snug' type is floor materials- form -color -color coordination, 'comfortable' type is wall materials -color, 'folksy' type is floor materials- form -wall materials. Second, Housing interior design attributes that affect the user's sensibility are distinctly different depending on the gender or the major.

\section{Methodology}

\section{Test subjects and procedure}

The test was performed from September 13 to October 11,2012 by the convenient sampling method limiting to the 118 male and females aged from 20s to 30 s living in Seoul and capital region using quota sampling for age. The place for test was limited to the lecture room or meeting room or seminar room of the general company or the resident center, and the pleasant test condition was maintain by limiting the number of persons to under 10 persons per test. The housing interior space images were presented by the beam projector, and to make the stimuli of the images same, the natural light was block with the black curtain and to maintain the illumination constantly, average 10 50 Lux was maintained by measuring the illumination from the center and 4 corners of the space. Before starting the test, the subjects for the test heard the sufficient explanation for the test by the researcher and start the test after being verified the understanding. Considering the time to take to answer the 8 questions per one image and to make the stimuli by each image same, image presentation was limited to 40 seconds per image, and the adjective of sensibility factor measured with Likert 7-point scale by the semantic differential scales. The general data on the subjects are shown in $<$ Table 1>.

Table 1. The Social Demographic Characteristic of the Subjects for the Test $\mathrm{n}=118$

\begin{tabular}{|c|c|c|}
\hline Social demographic characteristic & $\mathrm{f}$ & $\%$ \\
\hline \multicolumn{3}{|l|}{ Gender } \\
\hline Male & 55 & 46.5 \\
\hline Female & 63 & 53.4 \\
\hline \multicolumn{3}{|l|}{ Age } \\
\hline $20 \mathrm{~s}$ & 61 & 51.7 \\
\hline $30 \mathrm{~s}$ & 57 & 48.3 \\
\hline \multicolumn{3}{|l|}{ Residence } \\
\hline Seoul & 88 & 74.6 \\
\hline Capital region & 30 & 25.4 \\
\hline \multicolumn{3}{|l|}{ Level of Education } \\
\hline High school graduate & 7 & 6.0 \\
\hline College student/ graduate & 80 & 67.9 \\
\hline Graduate School student/graduate & 31 & 26.1 \\
\hline \multicolumn{3}{|l|}{ Marital status } \\
\hline Married & 33 & 27.8 \\
\hline Single & 85 & 72.2 \\
\hline \multicolumn{3}{|l|}{ Occupation } \\
\hline Self-employment & 5 & 4.2 \\
\hline Office worker & 21 & 17.8 \\
\hline Professions & 14 & 11.9 \\
\hline Managers & 18 & 15.3 \\
\hline Scrap workers, temporary $\&$ daily employees & 7 & 5.9 \\
\hline House wife & 11 & 9.3 \\
\hline Student & 41 & 34.7 \\
\hline Other & 1 & 0.8 \\
\hline
\end{tabular}




\section{The Evaluation tool}

The sensibility evaluation tool was composed of 8 pairs of sensibility evaluation item for 42 image $^{1)}$ samples limiting to the images around the living room and the general matters of the subjects. The general matters of the subjects were composed of age, gender, residence, academic background and profession. And the words of sensibility evaluation were 8 pairs ${ }^{2}$ of adjectives of 'cozy', 'practical', 'cheerful', 'traditional', 'unique', 'congenial', 'sensuous', 'gorgeous'.

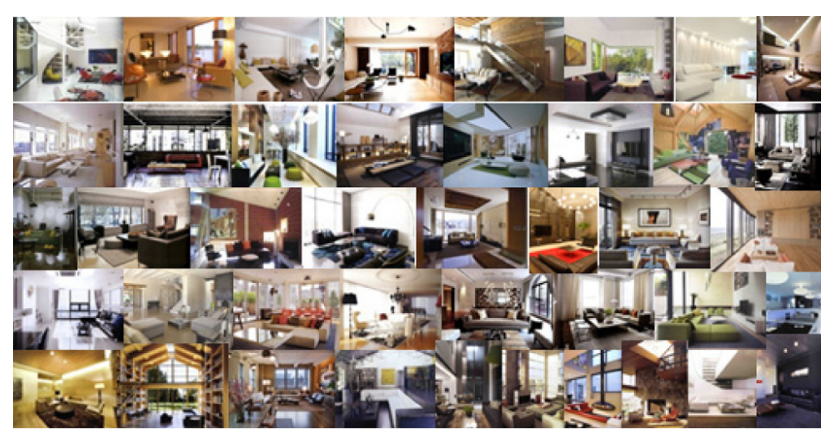

Figure 1. Housing Interior Space Images

\section{Data analysis}

In this study, to identify the interior design elements having influences on the sensibility, the empirical analysis was performed by quantifying the qualitative data of the interior space images using the type I quantification theory. To quantify the images, the interior design variables were divided into form, material, color. And referring to the previous researches by Park (2001), Yu (2008), Park, Yoon and Park (2012), there were composed of 17 interior design attributes, 88 categories.

The multiple correlation coefficient, which refers to

1) The image scale was constructed in two-dimensions of the sense of space and the type of space for the housing interior space images. The dimension of the 'sense of space' is explained by the axis of open-closed and the dimension of 'type of space', is explained by the axis of 'natural-artificial'. Such a structural model of the housing interior design attributes were divided into 8 groups. The 42 images representing each group were selected and the user-oriented housing interior space image tool was built by adding user's selective elements (Park, 2013).

2) To develop the user-oriented housing interior space sensibility evaluation tools, The first stage was the basic data collection stage and the words of user-oriented sensibility and the residential interior space images were collected, and in the 2ndstage, the sensibility assessment tool was developed by performing the investigation on the sensibility and residential interior space images from the general users and by selecting the sensibility factors and representative images for the residential space. The sensibility evaluation factors of this study were composed by the results of previous studies (Park, Yoon \& Park, 2012; Park, 2013). the relation between the entire evaluation variables and the factor of sensibility, the multiple regression analysis ${ }^{3)}$, the partial correlation coefficient, which means the degree of relation between the sensibility factor and each evaluation variable, and the category score, which refers to the degree of contribution of each category of the evaluation variable to the sensibility factor were obtained using above equation. In addition, to find out the correlation by the residual, the correlation between the sensibility by the intervening variable and the housing interior space design was analyzed through the DurbinWatson ${ }^{4)}$ multiple variate analysis.

\section{Results}

\section{Sensibility 'Cozy'}

The housing interior design attributes having significant influences on the sensibility 'cozy' were 12 attributes, and the influences by evaluation variables were represented as color, material and form in order.

In the attributes having positive and negative influences on the sensibility 'cozy', in case of evaluation variables of the type and material, the ceiling has greatest influences. The ceiling types having cubic effect with set-back (0.191), void (0.103), the spatial senses have positive influences on the sensibility 'cozy' but the ceilings having slope $(-0.445)$ or flat $(-0.319)$ have negative influences. In case of ceiling materials, all the other materials except the wood $(0.225)$ have negative influences. In the types of wall, the inclined wall (0.347) has positive influences. In the wall materials,

3) In the multiple regression analysis, for the descriptive variable selection method, there are all possible regression, step-wise regression and interactive variable selection method. Generally, the method (1), which makes the regression equation for organization of the descriptive variables and examines which regression equation is better, is used but it has a limit that the descriptive should be 4 to 5. Therefore, in this study, for the categories having more than 5 descriptive variables, the step-wise regression, which separates the valid variables and unnecessary variables by the significance of the each partial regression variables, was used. If the value of $F$ is less than 1, it is excluded considered as invalid variable (Noh, 2005). Since the possibility to occur the multicollinearity if the high correlation exists between the independent variables, when the tolerance is less than 0.1 , it is excluded from the judgment considering that it has problem in the multicollinearity (Song, 2009) 4) Statistic of Durbin-Watson is performed to find out the correlation of the residual (independency of the residual), and the criteria value becomes 2 which refers to normal distribution, which means that it does not have correlation with the residual. In the Durbin-Watson analysis results, if the value is close to 0 or 4 , it represents that the regression model is not appropriate due to having correlations among the residuals (Song, 2009). 
the fabric (0.338), which produces the natural line and softness, has greatest influences, and next great influences came from the line and roughness. In the flooring materials, the woods (0.267), marble (0.122) in order have positive influences. In the decorative elements in the interior space such as lighting equipments and furniture, for the type of lighting equipments, the ceiling lighting equipments not exposed such as architectural (0.181) and recessed (0.146) lightings, and the stand lighting, which is the mood lightings installed at floor, have positive influences, which means that the type of lightings that make the subdued mood without exposing lighting equipment has positive influence on the sensibility factor 'cozy'. In the arrange of furniture, the ' $L$ ' type (0.155) had positive influences and the straight type $(-0.440)$ and dispersed type (-0.242) represented to have negative influences, which means that furniture arrangement not excessively simple nor complicated having sense of changes and well arranged is correlated to the sensibility element 'cozy'.

In the evaluation variable of color, the attribute having greatest influence in all the floor, wall, ceiling, and furniture was brownish colors and its standard category score also higher than the other attributes, which is correlated to the property of the natural materials. The design attributes having secondary positive influences were represented as grey (0.129) for the floor, yellow (0.176) for the wall, white $(0.242)$ and orange $(0.148)$ for the furniture. This represents that the achromatic colors, which have the neutral feelings of calm and distinguished, in case of floor, the yellow and brownish colors, which gives bright and soft image, in case of wall, white, orange and brown color attribute, which give clean, bright and warm feelings, in case of furniture have the influences on the sensibility 'cozy'. In standard category scores of the overall color combination, the tone in tone $(0.564)$, tone on tone $(0.473)$, gradation (0.429), separation (0.424), complex (0.259), and repetition (0.122) in order have the influences. Except the emphasis, the natural color combination of the chromatic and achromatic colors in the series of warm color is related to the sensibility 'cozy'.

\section{Sensibility 'Practical'}

The design attributes having significant influence on the sensibility 'practical' were 9 attributes, and their influences on the evaluation variable represented in order of material, color and form.

In the evaluation variables of 'form', the type of
Table 2. Sensibility 'Cozy' and Interior Design Attributes

\begin{tabular}{|c|c|c|c|c|c|c|}
\hline Var. & $\begin{array}{c}\text { Design } \\
\text { Attribute }\end{array}$ & Categories & Item & $\begin{array}{l}\text { Range } \\
\text { (Partial) }\end{array}$ & $\begin{array}{c}\text { Dubin-Watson } \\
\qquad / R^{2} \\
\end{array}$ & C.S \\
\hline \multirow{13}{*}{ हี } & $\begin{array}{l}\text { Wall } \\
\text { Form }\end{array}$ & Slope & 12 & $\begin{array}{c}0.356 \\
(0.330)\end{array}$ & $\begin{array}{c}2.643 \\
R^{2}=.118^{*}\end{array}$ & 0.347 \\
\hline & \multirow{4}{*}{$\begin{array}{c}\text { Ceiling } \\
\text { Form }\end{array}$} & Flat & \multirow{4}{*}{6} & \multirow{4}{*}{$\begin{array}{c}0.636 \\
(0.428)\end{array}$} & \multirow{4}{*}{$\begin{array}{c}2.725 \\
R^{2}=0.457^{*}\end{array}$} & -0.319 \\
\hline & & Slope & & & & -0.445 \\
\hline & & Set-back & & & & 0.191 \\
\hline & & Void & & & & 0.103 \\
\hline & \multirow{5}{*}{$\begin{array}{c}\text { Lighting } \\
\text { Fixture } \\
\text { Form }\end{array}$} & Recessed & \multirow{5}{*}{7} & \multirow{5}{*}{$\begin{array}{c}0.631 \\
(0.461)\end{array}$} & \multirow{5}{*}{$\begin{array}{c}2.701 \\
R^{2}=.298^{* *}\end{array}$} & 0.146 \\
\hline & & Pendent & & & & -0.153 \\
\hline & & Track & & & & -0.450 \\
\hline & & Architectural & & & & 0.181 \\
\hline & & Stand & & & & 0.165 \\
\hline & \multirow{3}{*}{$\begin{array}{l}\text { Furniture } \\
\text { Arrange }\end{array}$} & Straight & \multirow{3}{*}{9} & \multirow{3}{*}{$\begin{array}{c}0.595 \\
(0.484)\end{array}$} & \multirow{3}{*}{$\begin{array}{c}2.376 \\
R^{2}=.244^{* *}\end{array}$} & -0.440 \\
\hline & & L Type & & & & 0.155 \\
\hline & & Dispersed & & & & -0.242 \\
\hline \multirow{12}{*}{ 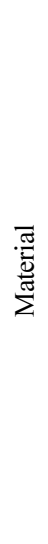 } & \multirow{3}{*}{ Floor } & Wood & \multirow{3}{*}{8} & \multirow{3}{*}{$\begin{array}{c}0.623 \\
(0.366)\end{array}$} & \multirow{3}{*}{$\begin{array}{c}2.668 \\
R^{2}=.268 * *\end{array}$} & 0.267 \\
\hline & & Marble & & & & 0.122 \\
\hline & & Tile & & & & -0.356 \\
\hline & \multirow{6}{*}{ Wall } & Wood & & & & 0.123 \\
\hline & & Marble & & & & 0.147 \\
\hline & & Natural Stone & 11 & 0.394 & 2.462 & 0.290 \\
\hline & & Painting & 11 & $(0.336)$ & $R^{2}=.241^{*}$ & 0.167 \\
\hline & & Glass & & & & 0.194 \\
\hline & & Fabric & & & & 0.338 \\
\hline & & Wood & & & & 0.225 \\
\hline & Ceiling & Glass & 4 & $\begin{array}{l}0.665 \\
(0.454)\end{array}$ & $\begin{array}{c}2.619 \\
R^{2}=280 * *\end{array}$ & -0.249 \\
\hline & & Steel/Concrete & & & & -0.440 \\
\hline & & White & & & & -0.082 \\
\hline & & Grey & & & & 0.129 \\
\hline & Floor & Black & 1 & 0.766 & 2.579 & -0.222 \\
\hline & Filoor & Red & 1 & $(0.540)$ & $R^{2}=.406 * * *$ & -0.171 \\
\hline & & Blue & & & & -0.253 \\
\hline & & Brown & & & & 0.513 \\
\hline & & Yellow & & & & 0.176 \\
\hline & Wall & Blue & 5 & $\begin{array}{l}0.651 \\
(0390)\end{array}$ & $\begin{array}{c}2.796 \\
R^{2}=226 *\end{array}$ & -0.256 \\
\hline & & Brown & & & & 0.395 \\
\hline & Ceilino & Grey & 10 & 0.543 & 2.645 & -0.389 \\
\hline & Cennng & Brown & 10 & $(0.186)$ & $R^{2}=.182 *$ & 0.154 \\
\hline$\frac{0}{0}$ & & White & & & & 0.242 \\
\hline & Furniture & Orange & & & & 0.148 \\
\hline & \& & Red & 2 & $\begin{array}{c}0.749 \\
(0360)\end{array}$ & $\begin{array}{c}2.481 \\
R^{2}=323 * *\end{array}$ & -0.307 \\
\hline & Accessory & Blue & & & & -0.110 \\
\hline & & Brown & & & & 0.442 \\
\hline & & Separation & & & & 0.424 \\
\hline & & Accent & & & & -0.134 \\
\hline & Color & Gradation & & & & 0.429 \\
\hline & Combina- & Repetition & 3 & $\begin{array}{l}0.698 \\
(0.551)\end{array}$ & $\begin{array}{c}2.519 \\
R^{2}=429 * * *\end{array}$ & 0.122 \\
\hline & tion & Tone on Tone & & & & 0.473 \\
\hline & & Tone in Tone & & & & 0.564 \\
\hline & & Complex & & & & 0.259 \\
\hline
\end{tabular}

$* p<.05 * * p<.01 * * * p<.001$ 
ceiling having set-back (0.097) has positive influences. And all the other attributes had negative influences. The attribute have greatest negative influences was slope $(-0.389)$ and next were void $(-0.297)$ and flat $(-0.155)$. Considering by the fact that the concentrated arrangement of windows with more than half of the area of windows in front had positive influences, if the space has lots of natural lights due to having big size of window, it has influences on the sensibility 'practical'. The arrangement of furniture by ' $\mathrm{L}$ ' type (0.359), parallel type (0.116), ' $ᄃ$ ' type (0.110) had positive influence in order. Therefore, it is observed that the arrangement of furniture that can utilize the space usefully without giving monotonous feeling has influence on the sensibility 'practical'.

In the evaluation variable of 'material', wall material, flooring material, and ceiling material represented to have influences in order. For the wall material, marble (0.502), fabric (0.292), glass (0.206), painting (0.130) represented to have positive influences in order. The familiar materials such as marble, fabric, glass, and painting which have been used a lot in the housing interior space, have positive influences. And the wall materials like natural stone, steel, exposed mass concrete, brick and woods, which generally have not been in housing space, have negative influences. It is observed that in the ceiling material, the familiar materials in the housing space have positive influences as in the wall materials as all the design attributes except the painting $(0.155)$ represented to have negative influences. In case of flooring material, the woods (0.145) represented to have positive influences, and tile $(-0.326)$ and carpet $(-0.170)$ represented to have negative influences. The reason why the exposed mass concrete, which is not familiar material to the users, represented to have positive influences differently from the wall and ceiling materials is deemed to be considered the visual practicality for the wall and ceiling and the practicality in use for the flooring material.

In the evaluation variable of 'color', the wall colors having positive influences were brown (0.371), white (0.263), yellow (0.219) in order, which means that the ordinary colors, which are familiar, and not distinguished to the users, are represented to have positive influences same as the materials. For the ceiling color, white (0.474) has greatest positive influences. In the color combination, producing the space changing difference in the brightness with same color represented to have influences on the sensibility 'practical'.
Table 3. Sensibility 'Practical' and Interior Design Attributes

\begin{tabular}{|c|c|c|c|c|c|c|}
\hline Var. & $\begin{array}{c}\text { Design } \\
\text { Attribute }\end{array}$ & Categories & Item & $\begin{array}{l}\text { Range } \\
\text { (Partial) }\end{array}$ & $\begin{array}{c}\text { Dubin-Watson } \\
/ R^{2} \\
\end{array}$ & C.S \\
\hline \multirow{9}{*}{ 言 } & \multirow{3}{*}{$\begin{array}{l}\text { Ceiling } \\
\text { Form }\end{array}$} & Flat & \multirow{3}{*}{5} & \multirow{3}{*}{$\begin{array}{c}0.486 \\
(0.340)\end{array}$} & \multirow{3}{*}{$\begin{array}{c}2.100 \\
R^{2}=.237^{*}\end{array}$} & -0.155 \\
\hline & & Slope & & & & -0.389 \\
\hline & & Void & & & & -0.297 \\
\hline & Window & Concentrated & \multirow{2}{*}{9} & \multirow{2}{*}{$\begin{array}{c}0.465 \\
(0.332)\end{array}$} & \multirow{2}{*}{$\begin{array}{c}1.815 \\
R^{2}=.173^{*} \\
\end{array}$} & 0.465 \\
\hline & Arrange & Dispersal & & & & 0.272 \\
\hline & & Straight & \multirow{4}{*}{3} & \multirow{4}{*}{$\begin{array}{c}0.524 \\
(0.370)\end{array}$} & \multirow{4}{*}{$\begin{array}{c}1.832 \\
R^{2}=.168 *\end{array}$} & -0.165 \\
\hline & \multirow{3}{*}{$\begin{array}{l}\text { Furniture } \\
\text { Arrange }\end{array}$} & L Type & & & & 0.359 \\
\hline & & ᄃ Type & & & & 0.110 \\
\hline & & Parallel & & & & 0.116 \\
\hline \multirow{12}{*}{ 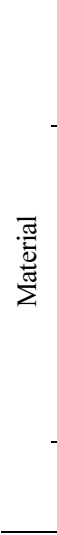 } & \multirow{3}{*}{ Floor } & Wood & \multirow{3}{*}{7} & \multirow{3}{*}{$\begin{array}{c}0.471 \\
(0.332)\end{array}$} & \multirow{3}{*}{$\begin{array}{c}1.981 \\
R^{2}=.240^{*}\end{array}$} & 0.145 \\
\hline & & Tile & & & & -0.326 \\
\hline & & Carpet & & & & -0.170 \\
\hline & \multirow{7}{*}{ Wall } & Marble & \multirow{7}{*}{1} & \multirow{7}{*}{$\begin{array}{c}0.801 \\
(0.450)\end{array}$} & \multirow{7}{*}{$\begin{array}{c}1.720 \\
R^{2}=.327 *\end{array}$} & 0.502 \\
\hline & & Natural Stone & & & & -0.299 \\
\hline & & Painting & & & & 0.130 \\
\hline & & Brick & & & & -0.103 \\
\hline & & Steel/Concrete & & & & -0.261 \\
\hline & & Glass & & & & 0.206 \\
\hline & & Fabric & & & & 0.292 \\
\hline & \multirow{2}{*}{ Ceiling } & Painting & \multirow{2}{*}{8} & \multirow{2}{*}{$\begin{array}{c}0.467 \\
(0.242)\end{array}$} & \multirow{2}{*}{$\begin{array}{c}1.920 \\
R^{2}=.157 *\end{array}$} & 0.155 \\
\hline & & Steel/Concrete & & & & -0.312 \\
\hline \multirow{14}{*}{$\frac{0}{0}$} & & White & & & & 0.263 \\
\hline & & Grey & & & & 0.106 \\
\hline & Wal & Yellow & 2 & 0.641 & 1.852 & 0.219 \\
\hline & wall & Red & 2 & $(0.351)$ & $R^{2}=.297 *$ & -0.122 \\
\hline & & Blue & & & & -0.270 \\
\hline & & Brown & & & & 0.371 \\
\hline & Ceiling & White & & 0.474 & 2.021 & 0.474 \\
\hline & Celling & Brown & 0 & $(0.327)$ & $R^{2}=.172 *$ & 0.336 \\
\hline & & Separation & & & & 0.320 \\
\hline & & Gradation & & & & 0.326 \\
\hline & Color & Repetition & 4 & 0.513 & 1.791 & -0.135 \\
\hline & tion & Tone on Tone & 4 & $(0.397)$ & $R^{2}=.300 * *$ & 0.378 \\
\hline & & Tone in Tone & & & & 0.136 \\
\hline & & Complex & & & & 0.120 \\
\hline
\end{tabular}

$* p<.05 * * p<.01 * * * p<.001$

\section{Sensibility 'Cheerful'}

The design attributes having significant influences on the sensibility 'cheerful' were represented 7 attributes and the influences by evaluation variables were represented as color, material and form in order.

In the evaluation variable of 'form', slope (0.171) and flat (0.018) ceilings had positive influence. In the evaluation variable of ceiling material, only the glass (0.279) represented to have positive influences. Among the wall materials, the woods (0.163) and brick (0.047) represented to have positive influence, and the fabric $(-0.347)$, steel/exposed mass concrete $(-0.240)$, natural 
stone $(-0.280)$, glass $(-0.176)$ in order represented to have negative influences. This represents that the type of the stable ceilings or narrow looking space like inclined or flat ceilings have influences on the sensibility 'cheerful' while the windows have negative influence. In addition, the simple and natural wall materials like woods or brick have influences on the sensibility 'cheerful' but using woods in the ceiling has negative influences.

In the evaluation variable of 'color', green, blue, red

Table 4. Sensibility 'Cheerful' and Interior Design Attributes

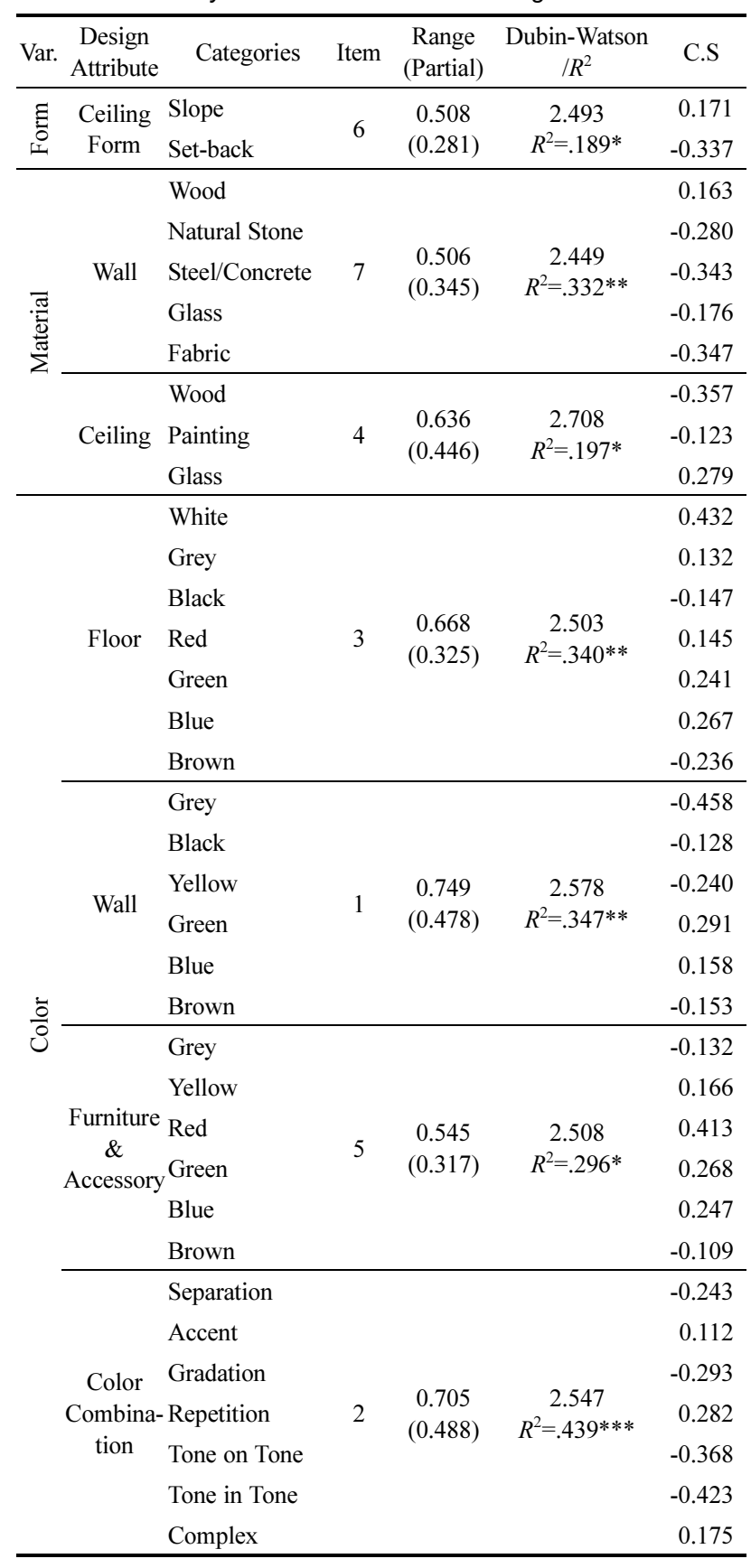

$* p<.05 * * p<.01 * * * p<.001$ colors represented to have positive influences among the colors of floor, wall, and the furniture having little differences in the order of influences. In case of wall color, the series of cold color represented to have greater influences as the influences were represented in the order of green $(0.291)$, blue $(0.158)$. In case of flooring color, white $(0.432)$ has the greatest positive influences. In among the colors of the furniture and accessories, total 6 colors represented to have positive influences except grey (-0.132), brown (-0.109), and black (-0.007). Diverse colors including white represented to have positive influences on the sensibility 'cheerful'. In the color combination, repetition (0.282), complex (0.175), and accent (0.112) in order around the diverse colors represented to have positive influences.

\section{Sensibility 'Traditional'}

The interior design attributes having significant influences of the sensibility 'traditional' were represented 5 attributes and the influences by evaluation variables were represented as color, form and material in order.

The unique design attribute having significantly positive influences is the type of lighting equipments such as stand (0.372), pendent (0.043), and recessed lighting (0.027), in order. And the standard category score of the stand lighting was relatively great influences compared with the other attributes. In the evaluation variable of 'material', only the flooring material represented to have positive influences, the woods (0.371) and exposed concrete $(0.150)$ in order had positive influences, which is considered that the exposed concrete, which associates with the woods and soil, the materials of traditional wooden floor have influences on the sensibility 'traditional'.

In case of evaluation variable the 'color', brown color represented to have positive influences on the floor, wall, ceiling, and furniture and accessories. In the floor color, brown (0.349) and green (0.066) were represented to have positive influence. In the color of furniture and accessories, orange (0.429), yellow (0.317), brown (0.304), black (0.219) in order. In the floor color, it was represented that the colors around the natural materials have influences and in case of furniture and accessories, differently from the floor, the colors around the series of warm color have influences harmonizing with the achromatic colors. The color combination that gives cheerfulness by arranging the tones uniformly and inserting and separating with the achromatic color represented to have influences. 
Table 5. Sensibility 'Traditional' and Interior Design Attributes

\begin{tabular}{|c|c|c|c|c|c|c|}
\hline Var. & $\begin{array}{l}\text { Design } \\
\text { Attribute }\end{array}$ & Categories & Item & $\begin{array}{l}\text { Range } \\
\text { (Partial) }\end{array}$ & $\begin{array}{c}\text { Dubin-Watson } \\
\qquad / R^{2}\end{array}$ & C.S \\
\hline \multirow{3}{*}{ 志 } & \multirow{3}{*}{$\begin{array}{l}\text { Lighting } \\
\text { Fixture } \\
\text { Form }\end{array}$} & Track & \multirow{3}{*}{4} & \multirow{3}{*}{$\begin{array}{c}0.612 \\
(0.453)\end{array}$} & \multirow{3}{*}{$\begin{array}{c}1.964 \\
R^{2}=.186^{*}\end{array}$} & -0.216 \\
\hline & & Architectural & & & & -0.240 \\
\hline & & Stand & & & & 0.372 \\
\hline \multirow{4}{*}{ 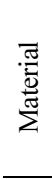 } & \multirow{4}{*}{ Floor } & Wood & \multirow{4}{*}{5} & \multirow{4}{*}{$\begin{array}{c}0.524 \\
(0.371)\end{array}$} & \multirow{4}{*}{$\begin{array}{c}1.773 \\
R^{2}=.187 *\end{array}$} & 0.371 \\
\hline & & Marble & & & & -0.153 \\
\hline & & Tile & & & & -0.078 \\
\hline & & Concrete & & & & 0.150 \\
\hline \multirow{13}{*}{$\frac{0}{0}$} & \multirow{3}{*}{ Floor } & White & \multirow{3}{*}{1} & \multirow{3}{*}{$\begin{array}{c}0.700 \\
(0.477)\end{array}$} & \multirow{3}{*}{$\begin{array}{c}1.987 \\
R^{2}=.379 * * *\end{array}$} & -0.351 \\
\hline & & Black & & & & -0.135 \\
\hline & & Brown & & & & 0.349 \\
\hline & \multirow{5}{*}{$\begin{array}{c}\text { Furniture } \\
\& \\
\text { Accessory }\end{array}$} & Black & \multirow{5}{*}{3} & \multirow{5}{*}{$\begin{array}{c}0.668 \\
(0.412)\end{array}$} & \multirow{5}{*}{$\begin{array}{c}2.182 \\
R^{2}=.271^{*}\end{array}$} & 0.219 \\
\hline & & Yellow & & & & 0.317 \\
\hline & & Orange & & & & 0.429 \\
\hline & & Red & & & & -0.239 \\
\hline & & Brown & & & & 0.304 \\
\hline & \multirow{5}{*}{$\begin{array}{l}\text { Color } \\
\text { Combina- } \\
\text { tion }\end{array}$} & Separation & \multirow{5}{*}{2} & \multirow{5}{*}{$\begin{array}{c}0.678 \\
(0.461)\end{array}$} & \multirow{5}{*}{$\begin{array}{c}1.911 \\
R^{2}=.348^{* *}\end{array}$} & 0.341 \\
\hline & & Gradation & & & & 0.175 \\
\hline & & Repetition & & & & -0.190 \\
\hline & & Tone in Tone & & & & 0.488 \\
\hline & & Complex & & & & 0.248 \\
\hline
\end{tabular}

${ }^{*} p<.05 * * p<.01 * * * p<.001$

\section{Sensibility 'Unique'}

The interior design attributes having significant influences on the sensibility 'unique' were 11 attributes and the influences by evaluation variables were represented as material, form and color in order.

In case of evaluation variable the 'form', the construction of wall, 1 side (0.471) and 2 sides (0.093) in order represented to have positive influences, and the 3 sides (-0.093) represented to have negative influences, which represents that the space receives the great influences by the graphic plot by the wall rather than giving the spatial sense with simple type constructed with single sided wall. In the ceiling types, slope (0.490), void (0.342), and flat $(0.230)$ in order represented to have positive influences. The type of ceilings that have inclined dynamically or the void producing openness by being opened represented to have influences rather than the ceiling types having set-backs or ribs. Regardless of type and arrangement of the window, having window represented to have influences on the sensibility 'unique'. In case of arrangement of furniture, straight type (0.153) and parallel type (0.135), in order, and in the lighting equipments, track lighting (0.184) represented to have positive influences, which means that in the constructing the space, the straight surface and lines represented to have influences on the sensibility 'unique'.
Table 6. Sensibility 'Unique’ and Interior Design Attributes

\begin{tabular}{|c|c|c|c|c|c|c|}
\hline Var. & $\begin{array}{c}\text { Design } \\
\text { Attribute }\end{array}$ & Categories & Item & $\begin{array}{l}\text { Range } \\
\text { (Partial) }\end{array}$ & $\begin{array}{l}\text { Dubin-Watson } \\
\qquad / R^{2}\end{array}$ & C.S \\
\hline \multirow{12}{*}{ ह్ } & \multirow{3}{*}{ Wall Con. } & 1 Surface & \multirow{3}{*}{6} & \multirow{3}{*}{$\begin{array}{c}0.564 \\
(0.408)\end{array}$} & \multirow{3}{*}{$\begin{array}{c}2.247 \\
R^{2}=.228^{* *}\end{array}$} & 0.471 \\
\hline & & 2 Surface & & & & 0.093 \\
\hline & & 3 Surface & & & & -0.093 \\
\hline & \multirow{4}{*}{$\begin{array}{l}\text { Ceiling } \\
\text { Form }\end{array}$} & Flat & \multirow{4}{*}{3} & \multirow{4}{*}{$\begin{array}{c}0.689 \\
(0.334)\end{array}$} & \multirow{4}{*}{$\begin{array}{c}2.321 \\
R^{2}=.335^{* *}\end{array}$} & 0.230 \\
\hline & & Slope & & & & 0.490 \\
\hline & & Set-back & & & & -0.199 \\
\hline & & Void & & & & 0.342 \\
\hline & $\begin{array}{l}\text { Window } \\
\text { Area }\end{array}$ & Nothing & 9 & $\begin{array}{c}0.420 \\
(0.338)\end{array}$ & $\begin{array}{c}2.040 \\
R^{2}=.115^{*}\end{array}$ & 0.327 \\
\hline & & Straight & \multirow{4}{*}{10} & \multirow{4}{*}{$\begin{array}{c}0.414 \\
(0.298)\end{array}$} & \multirow{4}{*}{$\begin{array}{c}2.143 \\
R^{2}=.147 *\end{array}$} & 0.153 \\
\hline & Furniture & L Type & & & & -0.260 \\
\hline & Arrange & ᄃ Type & & & & -0.261 \\
\hline & & Parallel & & & & 0.135 \\
\hline \multirow{11}{*}{ 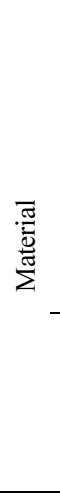 } & \multirow{7}{*}{ Wall } & Wood & \multirow{7}{*}{2} & \multirow{7}{*}{$\begin{array}{c}0.735 \\
(0.607)\end{array}$} & \multirow{7}{*}{$\begin{array}{c}1.664 \\
R^{2}=.520 * * *\end{array}$} & 0.185 \\
\hline & & Marble & & & & -0.481 \\
\hline & & Natural Stone & & & & 0.144 \\
\hline & & Painting & & & & -0.136 \\
\hline & & Steel/Concrete & & & & 0.254 \\
\hline & & Glass & & & & -0.234 \\
\hline & & Fabric & & & & -0.579 \\
\hline & \multirow{4}{*}{ Ceiling } & Wood & \multirow{4}{*}{1} & \multirow{4}{*}{$\begin{array}{c}0.829 \\
(0.693)\end{array}$} & \multirow{4}{*}{$\begin{array}{c}2.147 \\
R^{2}=.239 *\end{array}$} & -0.480 \\
\hline & & Painting & & & & -0.637 \\
\hline & & Glass & & & & 0.192 \\
\hline & & Steel/Concrete & & & & -0.100 \\
\hline & & Grey & & & & -0.256 \\
\hline & Floor & Red & 7 & 0.485 & 2.249 & 0.180 \\
\hline & F1001 & Green & 1 & $(0.246)$ & $R^{2}=.168^{*}$ & 0.185 \\
\hline & & Brown & & & & -0.300 \\
\hline & & White & & & & -0.441 \\
\hline & & Grey & & & & -0.375 \\
\hline & & Black & & & & -0.138 \\
\hline & Wall & Yellow & 5 & 0.601 & 1.897 & -0.269 \\
\hline & wall & Red & 3 & $(0.430)$ & $R^{2}=.363^{* *}$ & -0.119 \\
\hline & & Green & & & & 0.160 \\
\hline & & Blue & & & & 0.159 \\
\hline & & Brown & & & & 0.102 \\
\hline 흠 & Ceiling & White & 11 & 0.382 & 2.243 & -0.361 \\
\hline ن & Cenning & Brown & 11 & $(0.436)$ & $R^{2}=.226^{*}$ & -0.257 \\
\hline & & White & & & & 0.105 \\
\hline & & Black & & & & -0.178 \\
\hline & Furniture & Yellow & & & & -0.254 \\
\hline & $\&$ & Orange & 4 & $\begin{array}{c}0.612 \\
(0320)\end{array}$ & $\begin{array}{c}2.370 \\
R^{2}=270 *\end{array}$ & 0.171 \\
\hline & Accessory & Red & & & & 0.358 \\
\hline & & Green & & & & 0.307 \\
\hline & & Brown & & & & -0.118 \\
\hline & & Accent & & & & 0.213 \\
\hline & Color & Gradation & & & & -0.259 \\
\hline & Combina- & Repetition & 8 & $\begin{array}{l}0.478 \\
(0.352)\end{array}$ & $\begin{array}{c}1.818 \\
R^{2}=221 *\end{array}$ & 0.191 \\
\hline & tion & Tone on Tone & & & & -0.265 \\
\hline & & Tone in Tone & & & & -0.195 \\
\hline
\end{tabular}

$* p<.05 * * p<.01 * * * p<.001$ 
In the evaluation variable the material, the ceiling material and wall material, in order represented to have influences, and in case of ceiling material, glass (0.192) represented to have positive influences. That is, the negative influences represented greater than positive influences. In case of wall material, the attribute having positive influences were represented in the order of steel/exposed mass concrete $(0.254)$, woods $(0.185)$, natural stone $(0.144)$, but since there is no great difference in the standard category score, it is observed that the influences of these 3 attributes are similar. In addition, it represented that the negative influences were greater than positive influences, and the negative influences were represented in the order of fabric (-0.579), marble $(-0.481)$, glass $(-0.234)$, painting $(-0.136)$. As such it is observed that the materials used mainly in existing housing space have negative influences on the sensibility 'unique'.

In the evaluation variable color, in case of the floor color, green $(0.185)$, red $(0.180)$ in order represented to have positive influences. In the wall color, green $(0.160)$, blue (0.159) and brown (0.102), and in the ceiling color, all the colors except the grey $(0.021)$ represented to have negative influences, and the value of negative influences was greater than the value of positive influences. On the other hand, in case the furniture color, the standard category score having positive influences were higher representing in the order of red (0.358), green (0.307), orange (0.171) and white (0.105) in order. In the color combination, accent (0.213) and repetition (0.191) in order represented to have positive influences and the rest colors represented the negative influences. In the evaluation variable 'color', except the furniture color, the scores of negative influence were greater than positive influences, which represents that the materials and color familiar to the users have negative influences. The attribute having positive influences in the color combination were the accent and repetition, and the color combination that gives individuality by distinguishing with contrast colors or using 2 or more colors repeatedly represented to have influences.

\section{Sensibility 'Congenial'}

The interior design attribute having significant influences on the sensibility 'congenial' were 9 attributes and the influences by evaluation variables were represented as form, color and material in order.

The attribute having greatest influences in the evaluation variable 'form' was the arrangement of furniture, and all the design attribute except the dispersed type (0.151) represented to have negative influences. The 3-surfaced wall (0.206) represented to have positive influences. It represented that the stable symmetric space having cubic effects has influences. In the type of ceiling, flat (0.341), set-back (0.194) represented the positive influences and the void type of ceiling $(-0.155)$ represented the negative influences. In the type of fixed components, symmetric, simple and stable types represented to have influences rather than the sense of wide space. In the window, the dispersed type having less than half of the area represented to have positive influences and in the lighting equipment, stand (0.365), pendent (0.201), and track lighting (0.121) represented to have positive influences.

In the evaluation variable 'material', only the wall material represented to having significant influences, brick (0.224), fabric (0.104) represented the positive influence and the steel/exposed concrete $(-0.383)$, natural stone $(-0.251)$, in order represented the negative influences. It is observed that the wall material having small sized natural textual represented to have influences on the sensibility 'congenial' than the rough, atypical and natural materials.

In the evaluation variable 'color', furniture color, wall color and principle of color combination in order represented to have influences. In case of furniture color, all 9 colors of yellow (0.682), orange $(0.463)$, black $(0.425)$, brown (0.399), blue (0.282), green $(0.242)$, grey $(0.164)$, red $(0.077)$ and white $(0.015)$ in order represented to have positive influences. That is, when the diverse colors are produces in the space harmonizing, the sensibility 'congenial' will be received the influences. The series of warn color than the series of cold color and in the achromatic colors, black, grey and white in order represented to have greater positive influences. The wall color was calculated less than standard category score than furniture color, and represented to have greater negative influences than the positive influences. Above all, the attributes having positive influences were green (0.174), red (0.130), brown (0.120), blue (0.088) and white $(0.027)$ in order. In the color combination, the complex color combination by diverse colors and the color combination of tone on tone that arranges the color unifying the tone although the color is different represent to have influences, the unified color combination by diverse color in the space were significant. 
Table 7. Sensibility 'Congenial' and Interior Design Attributes

\begin{tabular}{|c|c|c|c|c|c|c|}
\hline Var. & $\begin{array}{c}\text { Design } \\
\text { Attribute }\end{array}$ & Categories & Item & $\begin{array}{l}\text { Range } \\
\text { (Partial) }\end{array}$ & $\begin{array}{c}\text { Dubin-Watson } \\
\qquad / R^{2} \\
\end{array}$ & C.S \\
\hline \multirow{15}{*}{ 言 } & & 1 Surface & \multirow{3}{*}{4} & \multirow{3}{*}{$\begin{array}{c}0.556 \\
(0.249)\end{array}$} & \multirow{3}{*}{$\begin{array}{c}1.680 \\
R^{2}=.160 *\end{array}$} & -0.350 \\
\hline & Construc- & 2 Surface & & & & -0.206 \\
\hline & & 3 Surface & & & & 0.206 \\
\hline & \multirow{3}{*}{$\begin{array}{l}\text { Ceiling } \\
\text { Form }\end{array}$} & Flat & \multirow{3}{*}{6} & \multirow{3}{*}{$\begin{array}{c}0.496 \\
(0.242)\end{array}$} & \multirow{3}{*}{$\begin{array}{c}1.874 \\
R^{2}=.166^{*}\end{array}$} & 0.341 \\
\hline & & Set-back & & & & 0.194 \\
\hline & & Void & & & & -0.155 \\
\hline & Window & Concentrated & \multirow[t]{2}{*}{9} & \multirow{2}{*}{$\begin{array}{c}0.431 \\
(0.316)\end{array}$} & \multirow{2}{*}{$\begin{array}{c}1.700 \\
R^{2}=.152^{*}\end{array}$} & 0.063 \\
\hline & \multirow[t]{2}{*}{ Arrange } & Dispersal & & & & 0.431 \\
\hline & & Recessed & \multirow{5}{*}{5} & \multirow{5}{*}{$\begin{array}{c}0.543 \\
(0.326)\end{array}$} & \multirow{5}{*}{$\begin{array}{c}1.848 \\
R^{2}=.195^{*}\end{array}$} & -0.147 \\
\hline & \multirow{4}{*}{$\begin{array}{c}\text { Lighting } \\
\text { Fixture } \\
\text { Form }\end{array}$} & Pendent & & & & 0.201 \\
\hline & & Track & & & & 0.121 \\
\hline & & Architectural & & & & -0.178 \\
\hline & & Stand & & & & 0.365 \\
\hline & Furniture & L Type & \multirow{2}{*}{3} & \multirow{2}{*}{$\begin{array}{c}0.595 \\
(0.369)\end{array}$} & \multirow{2}{*}{$\begin{array}{c}2.089 \\
R^{2}=.238^{*}\end{array}$} & -0.344 \\
\hline & Arrange & Dispersed & & & & 0.151 \\
\hline \multirow{4}{*}{ 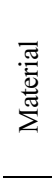 } & \multirow{4}{*}{ Wall } & Natural Stone & \multirow{4}{*}{2} & \multirow{4}{*}{$\begin{array}{c}0.607 \\
(0.354)\end{array}$} & \multirow{4}{*}{$\begin{array}{c}1.698 \\
R^{2}=.255^{* *}\end{array}$} & -0.251 \\
\hline & & Brick & & & & 0.224 \\
\hline & & Steel/Concrete & & & & -0.383 \\
\hline & & Fabric & & & & 0.104 \\
\hline \multirow{18}{*}{$\frac{0}{0}$} & \multirow{7}{*}{ Wall } & White & & & & 0.027 \\
\hline & & Grey & & & & -0.318 \\
\hline & & Black & & & & -0.164 \\
\hline & & Red & 7 & $\begin{array}{c}0.492 \\
(0217)\end{array}$ & $\begin{array}{c}1.562 \\
R^{2}=182 *\end{array}$ & 0.130 \\
\hline & & Green & & & & 0.174 \\
\hline & & Blue & & & & 0.088 \\
\hline & & Brown & & & & 0.120 \\
\hline & & White & & & & 0.015 \\
\hline & & Grey & & & & 0.164 \\
\hline & & Black & & & & 0.425 \\
\hline & Furniture & Yellow & & & & 0.682 \\
\hline & \& & Orange & 1 & $\begin{array}{c}0.682 \\
(0.653)\end{array}$ & $\begin{array}{c}2.003 \\
R^{2}=.507 * *\end{array}$ & 0.463 \\
\hline & Accessory & Red & & & & 0.077 \\
\hline & & Green & & & & 0.242 \\
\hline & & Blue & & & & 0.282 \\
\hline & & Brown & & & & 0.399 \\
\hline & Color & Tone on Tone & & 0.458 & 1.936 & -0.106 \\
\hline & $\begin{array}{c}\text { Combina- } \\
\text { tion }\end{array}$ & Complex & 8 & $(0.322)$ & $R^{2}=.150^{*}$ & 0.352 \\
\hline
\end{tabular}

\section{Sensibility 'Sensuous'}

The interior design attributes having influences on the sensibility 'sensuous' were 8 , and the influences by evaluation variables were represented as color, form and material in order.

The ceiling type represented to have greatest influence as the sensibility 'cozy', 'cheerful', and 'unique'. The slope (0.490) and void types of ceiling (0.168) which produce the dynamic and spatial sense, represented to have positive influences in order. In case of window, the attribute of the window represented to have negative influences as the front concentrated type having more than half of the area $(-0.362)$ represented to have negative influences, and the artificial light represented to have greater influences that the natural light. In the lighting equipment, the element protruded from the ceiling such as pendent (0.152) and track lightings (0.144) represented to have positive influences, and the lighting equipments such as surface (-0.243) and architectural (-0.195), which do not protruded greatly in the interior space represented to have negative influences. In the arrangement of furniture, the dispersed type (0.064), which made the space freely and is applied as decorative element, represented to have positive influences.

In case of evaluation variable 'material', only the wall material except the wall and ceiling represented to have sensibility 'sensuous', and represented the positive influence in the order of woods (0.095), natural stone (0.092), brick (0.073), steel/exposed concrete (0.054). Fabric (-0.446), marble (-0.429), glass (-0.219) represented the negative influences in order. Comparing with the sensibility 'unique', the attributes having positive influences were same but order was different. However, it is observed that the attributes having negative influences represented in same order, which means that the familiar materials such as fabric, marble, glass and painting, which are familiar to the users, have negative influences for both sensibility 'unique' and 'sensuous'.

In the evaluation variable 'color', the wall color, furniture color and the principle of color combination represented to have influences in order, and in case of wall color, all the other colors except green (0.106) represented to have negative influence. The color having greatest negative influences was grey $(-0.488)$ and the white (-0.356), black $(-0.257)$ and yellow (-0.251) followed after in order. The achromatic colors represented the negative influences on the sensibility 'sensuous'. In case of furniture color, red (0.396), green (0.346), orange $(0.241)$ and white $(0.127)$ represented the positive influences in order, and the grey $(-0.183)$, black $(-0.112)$ represented the negative influences, which means that the lots of attributes have positive influences than the sensibility 'unique', and the achromatic colors have negative influence on the sensibility 'sensuous' except the white. In the color combination, the accent (0.151), and repetition $(0.122)$ represented the positive influences in order. 
Table 8. Sensibility 'Sensuous' and Interior Design Attributes

\begin{tabular}{|c|c|c|c|c|c|c|}
\hline Var. & $\begin{array}{c}\text { Design } \\
\text { Attribute }\end{array}$ & Categories & Item & $\begin{array}{l}\text { Range } \\
\text { (Partial) }\end{array}$ & $\begin{array}{c}\text { Dubin-Watson } \\
/ R^{2} \\
\end{array}$ & C.S \\
\hline \multirow{10}{*}{ II } & \multirow{4}{*}{$\begin{array}{c}\text { Ceiling } \\
\text { Form }\end{array}$} & Flat & \multirow{4}{*}{1} & \multirow{4}{*}{$\begin{array}{c}0.618 \\
(0.295)\end{array}$} & \multirow{4}{*}{$\begin{array}{c}2.529 \\
R^{2}=.262 *\end{array}$} & -0.257 \\
\hline & & Slope & & & & 0.251 \\
\hline & & Set-back & & & & -0.367 \\
\hline & & Void & & & & 0.168 \\
\hline & $\begin{array}{l}\text { Window } \\
\text { Arrange. }\end{array}$ & Concentrated & 8 & $\begin{array}{c}0.362 \\
(0.317)\end{array}$ & $\begin{array}{c}2.367 \\
R^{2}=.137 *\end{array}$ & -0.362 \\
\hline & \multirow{4}{*}{$\begin{array}{c}\text { Lighting } \\
\text { Fixture } \\
\text { Form }\end{array}$} & Surface & \multirow{4}{*}{7} & \multirow{4}{*}{$\begin{array}{c}0.395 \\
(0.202)\end{array}$} & \multirow{4}{*}{$\begin{array}{c}2.321 \\
R^{2}=.133 *\end{array}$} & -0.243 \\
\hline & & Pendent & & & & 0.152 \\
\hline & & Track & & & & 0.144 \\
\hline & & Architectural & & & & -0.195 \\
\hline & $\begin{array}{c}\text { Furniture } \\
\text { Arrange }\end{array}$ & L Type & 6 & $\begin{array}{c}0.410 \\
(0.324)\end{array}$ & $\begin{array}{c}2.498 \\
R^{2}=.120^{*}\end{array}$ & -0.336 \\
\hline \multirow{3}{*}{$\begin{array}{l}\frac{\pi}{0} \\
\frac{\pi}{2} \\
\sum\end{array}$} & \multirow{3}{*}{ Wall } & Marble & \multirow{3}{*}{5} & \multirow{3}{*}{$\begin{array}{c}0.541 \\
(0.424)\end{array}$} & \multirow{3}{*}{$\begin{array}{c}2.276 \\
R^{2}=.337 * *\end{array}$} & -0.429 \\
\hline & & Glass & & & & -0.219 \\
\hline & & Fabric & & & & -0.446 \\
\hline \multirow{17}{*}{$\frac{0}{0}$} & \multirow{5}{*}{ Wall } & White & \multirow{5}{*}{2} & \multirow{5}{*}{$\begin{array}{c}0.594 \\
(0.426)\end{array}$} & \multirow{5}{*}{$\begin{array}{c}2.099 \\
R^{2}=.291 *\end{array}$} & -0.356 \\
\hline & & Grey & & & & -0.488 \\
\hline & & Black & & & & -0.257 \\
\hline & & Yellow & & & & -0.251 \\
\hline & & Green & & & & 0.106 \\
\hline & & White & & & & 0.127 \\
\hline & & Grey & & & & -0.183 \\
\hline & Furniture & Black & 3 & 0.579 & 2.278 & -0.112 \\
\hline & Accessory & Orange & $J$ & $(0.332)$ & $R^{2}=.308^{* *}$ & 0.241 \\
\hline & & Red & & & & 0.396 \\
\hline & & Green & & & & 0.346 \\
\hline & \multirow{6}{*}{$\begin{array}{l}\text { Color } \\
\text { Combina- } \\
\text { tion }\end{array}$} & Separation & \multirow{6}{*}{4} & \multirow{6}{*}{$\begin{array}{c}0.570 \\
(0.461)\end{array}$} & \multirow{6}{*}{$\begin{array}{c}2.313 \\
R^{2}=.320^{* *}\end{array}$} & -0.177 \\
\hline & & Accent & & & & 0.151 \\
\hline & & Gradation & & & & -0.304 \\
\hline & & Repetition & & & & 0.122 \\
\hline & & Tone on Tone & & & & -0.419 \\
\hline & & Tone in Tone & & & & -0.236 \\
\hline
\end{tabular}

$* p<.05 * * p<.01 * * * p<.001$

\section{Sensibility 'Gorgeous'}

The design attribute having significant influences on the sensibility 'gorgeous' were 5, and the influences by evaluation variables were represented as color and form in order.

The color among the 3 evaluation variable worked as the most important attribute, and represented influences in the order of principle of color combination, floor color, wall color and furniture color. In case of floor color, white (0.439), blue (0.346) and red (0.337) represented the positive influences in order, and the brown $(-0.225)$ and grey $(-0.056)$ represented the negative influences in order, which is deemed to have relation with that the flooring material wood represented as negative attribute, and the blue, red or blackish carpet mostly on the white floor represented the influences on the sensibility 'gorgeous'. In the wall color, all the colors except the blue (0.270), green (0.112) and red (0.024) represented the negative influences. Like the floor, in the wall, the bluish colors (0.270) represented the greatest influences. In addition, as the brownish colors $(-0.382)$ represented the greatest negative influences as in the case of floor, it is deemed to be remained the negative influences on the woods in the color just like the wall. In the furniture colors, the standard category score of intense red (0.521) were higher than other color. And as the next colors having positive influences were green (0.272), blue (0.191), and the colors having negative influences were yellow (-0.126) and black (-0.116) in order, the score of colors having positive influences on the sensibility 'gorgeous' was higher than that of colors having negative influences. So, the colors having influences on the sensibility 'gorgeous' were the red, green, blue. In the color combination, accent (0.588), repetition (0.339) and complex (0.244) represented the positive influences in order. As in case of floor and furniture color, the positive score of the standards category relatively higher than negative score, which demonstrates that the color having influences on the sensibility 'gorgeous' are working positively. In the evaluation variable 'form', only the ceiling type represented the influences and among the type of ceiling, inclined ceiling (0.382) and void type of ceiling (0.163) represented the positive influences, which means that the rhythmic attribute granted by ceiling plays the important role in the sensibility 'gorgeous'

\section{Sensibility type and interior design application elements}

(1) For the sensibility 'cozy', the color was represented the most important. Particularly, the color and material of the floor, the furniture color and arrangement should be considered. For the color, the floor should be grey, wall is yellow, furniture and fixture are used the color combination of tone in tone together with orange around the brown of the floor, wall, ceiling and the furniture and accessory. The flooring materials should be two material using woods or marble with carpet, and for the ceiling, wood must be used. The material of wall must use fabric, natural stone, and glass. The dynamic cubic effects must be created with the inclined wall or having set-back and the vertical space sense must be produced with the set-back or void ceiling. For the lighting equipment, the architectural or buried type of lighting 
Table 9. Sensibility 'Gorgeous' and Interior Design Attributes

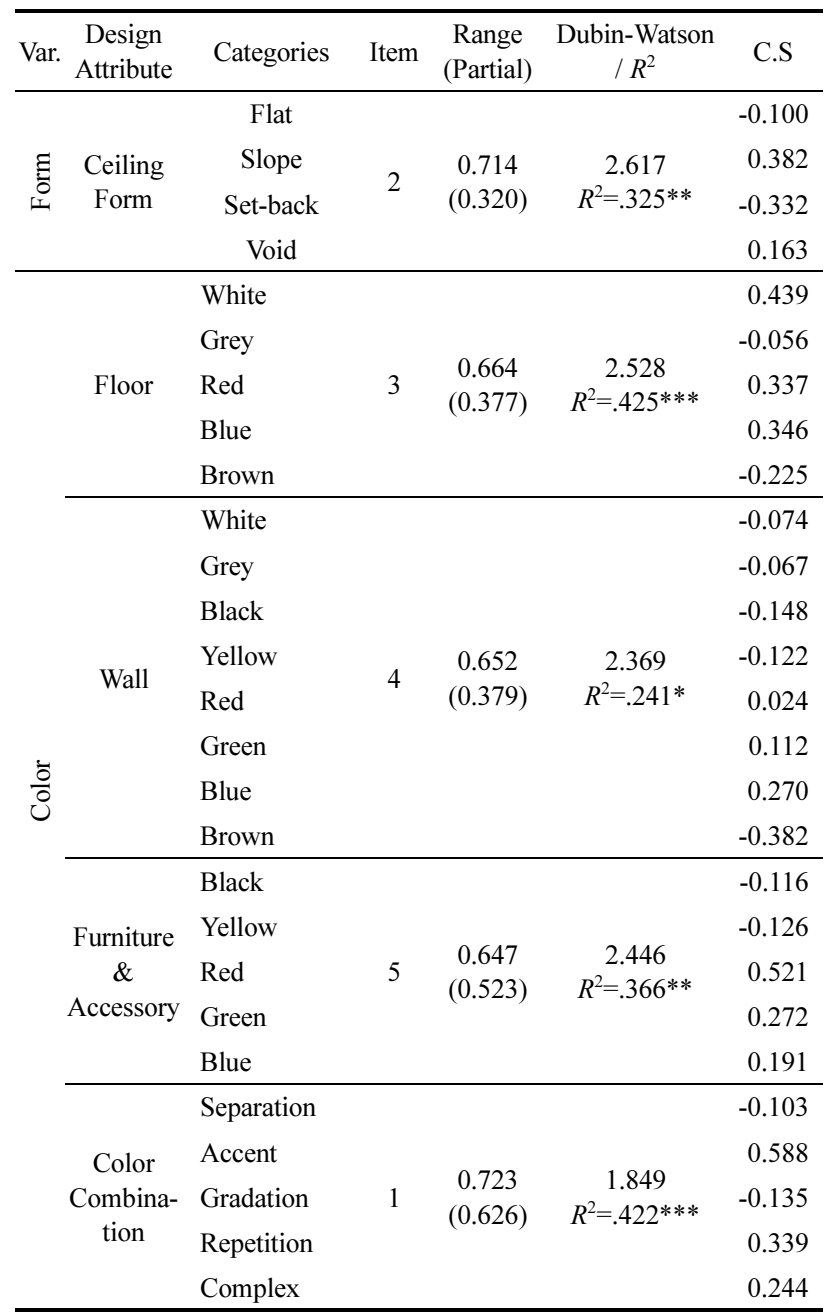

${ }^{*} p<.05 * * p<.01 * * * p<.001$

equipment that can make bright illumination without revealing the lighting equipment must be used to produce the soft mood by the artificial light without window. And the subdued effects can be added by the

Table 10. The Interior Design Application Elements of Sensibility Cozy'

\begin{tabular}{lcc}
\hline Variable & Design Attributes & Application Element \\
\hline \multirow{3}{*}{ Color } & Floor & Brown+Grey \\
& Wall & Brown+Yellow \\
& Ceiling & Brown \\
& Color Combination & Brown+White/Orange \\
Material & Floor & Tone in Tone \\
& Wall & Wood /Mable+Carpet \\
& Ceiling & Fabric/Natural Stone/Glass \\
& Wall Form & Wood \\
\hline \multirow{2}{*}{ Form } & Ceiling Form & Slope/Set-back \\
& Window Area & Set-back/Void \\
& Lighting Fixture Form & Architectural/Recessed+Stand \\
& Furniture Arrangement & L Type/ᄃ Type \\
\hline
\end{tabular}

partial lighting with stand type lighting equipment. For the furniture arrangement, the ' $L$ ' or ' $ᄃ$ ' type furniture arrangement can be used to produce the space not too simple but having sense of the changes.

(2) The most important assessment variable to produce the space of sensibility 'practical' is the material. Especially, the material, color, and form around the wall should be considered. The wall is to be constructed with concentrated window having more than half of the wall area and wall finished with marble, and the amount of light flowed through the window is to be controlled by fabric. The materials commonly used in existing housing space must be used, and the woods for floor, marble for wall and the ceiling finished with painting must be used for durability and easier maintenance. The vertically open feeling must be given with the setback ceiling that the height of ceiling is raised efficiently, and the horizontally open feeling is to be produced visually with the front glass. The furniture can be arranged with ' $L$ ' type arrangement in order to utilize the space much widely, or if the users' community is focused rather than the utilization of the space, the parallel type furniture arrangement is to be applied. For the wall color, brown as dominant color and white and yellow can be used as auxiliary color. For the ceiling color, the effect that the space is seemed to be wider can be produced by brightening up with white. That is, the familiar and acceptable design for the user must be used for the color and materials of floor, wall and the ceiling, which are the fixed elements of the space, and the uniformity and softness are to be produced by giving changes in the difference of brightness successively with the color combination of tone on tone or gradation which are not distinguished easily. And the entire space can be emphasized with cheerfulness by the color

Table 11. The Interior Design Application Elements of Sensibility 'Practical'

\begin{tabular}{ccc}
\hline Variable & Design Attributes & Application Element \\
\hline \multirow{3}{*}{ Material } & Floor & Wood/Exposed Concrete \\
& Wall & Mable/Fabric/Glass \\
& Ceiling & Painting \\
\hline \multirow{2}{*}{ Color } & Wall & Brown/White/Yellow \\
& Ceiling & White/Brown \\
\hline \multirow{4}{*}{ Form } & Ceiling Form & Tone on Tone \\
& Window Form & Set-back \\
& Window Area & Full Type \\
& Window Arrangement & more than $1 / 2$ \\
& Furniture Arrangement & Concentrated \\
& & L Type/Parallel \\
\hline
\end{tabular}


combination of separation in the chromatic and yellow colors of furniture and accessory.

(3) The most important assessment variable to produce the sensibility space 'cheerful' is the color. Particularly, the color and material around the wall must be considered. For the floor, white can be used as dominant color, and the tile or marble that the space is emphasized by the cold colors can be used. The color for the wall can be used around the cold color such as green and blue, and for the color combination for the furniture and fixture, more than 2 colors among white, cold colors, etc. can be repeated or the complex color combination can be used. The certain order should be maintained distinguishing as a whole and the space having individuality should be produced. The skylight rather than window, that is, using the glass in the ceiling that eases the heaviness from the ceiling maximizes the construction of the space for sensibility 'cheerful'. For the wall, the simple but natural effects can be made by using the material having small size and felt lighter such as natural woods, brick, etc. The stable and a little bit narrow-looking closed space can be produced with the inclined or flat ceiling without window. The diagonal element of the inclined ceiling and the linear element of the lighting equipment having protruded form (track or pendent type) work decorative effects in the space.

Table 12. The Interior Design Application Elements of Sensibility 'Cheerful'

\begin{tabular}{lcc}
\hline Variable & Design Attributes & Application Element \\
\hline \multirow{2}{*}{ Color } & Floor & White+Blue/Green \\
& Wall & Green/blue \\
& Furniture \& Accessory & Red/Green/Blue \\
& Color Combination & Repetition \\
\hline \multirow{2}{*}{ Material } & Wall & Wood+Brick \\
& Ceiling & Glass \\
\hline \multirow{2}{*}{ Form } & Ceiling Form & Slope/Flat \\
& Window Area & Nothing \\
& Lighting Fixture Form & Track/Pendent
\end{tabular}

(4) The most important assessment variable to produce the space of sensibility 'traditional' is the color. Particularly the color and material around the floor should be considered. The color of all the fixed and decorative components is made based on the brown color. The furniture and fixture should produce the uniformity and cheerfulness in the space by color combination of tone in tone that makes the tone uniform around the warm colors such as orange and yellow or color combination of separation that harmonizes with the achromatic colors.
The ceiling material sand flooring material should produced the rough and soft textures at the same time by using woods for the ceiling material and the exposed concrete, which associate with the natural woods or soil, as flooring material. The materials that produce natural and free lines should be used. The dispersed type of window having more than half of the wall area should be used, and the stand type lighting equipment will work as decorative element. The furniture and accessory are arranged in formal symmetric parallel type or ' $ᄃ$ ' type.

Table 13. The Interior Design Application Elements of Sensibility 'Traditional'

\begin{tabular}{ccc}
\hline Variable & Design Attributes & Application Element \\
\hline \multirow{2}{*}{ Color } & Floor & Brown+Green \\
& Furniture \& Accessory & Brown+Orange/Yellow \\
& Color Combination & Tone in Tone \\
\hline \multirow{2}{*}{ Material } & Floor & Wood/Exposed Concrete \\
& Wall & Fabric+Brick \\
\hline \multirow{2}{*}{ Form } & Window Area & more than $1 / 2$ \\
& Window Arrangement & Dispersed \\
& Lighting Fixture Form & Stand \\
\hline
\end{tabular}

(5) The most important assessment variable to produce the space of sensibility 'unique' is the material. Particularly the material and form around the ceiling should be considered. The tile for flooring material, the glass for ceiling material and the materials not commonly used in existing housing space such as steel/exposed concrete, woods, natural stone, etc must be used for wall material. The wall should be made by decorative effects with graphical expression by making singlesurface without window rather than the space sense in the entire space. The ceiling should express the dynamic

Table 14. The Interior Design Application Elements of Sensibility 'Unique'

\begin{tabular}{ccc}
\hline Variable & Design Attributes & Application Element \\
\hline \multirow{2}{*}{ Material } & Wall & Steel/Exposed Concrete/Wood/ \\
& Ceiling & Natural Stone \\
& Wall Construction & Glass \\
Form & Ceiling Form & Slope/Void \\
& Window Area & Nothing \\
& Furniture Arrangement & Straight/Parallel \\
\hline \multirow{3}{*}{ Color } & Light & Artificial \\
& Floor & Green/Red \\
& Wall & Green/Blue/Brown \\
& Ceiling & Grey \\
& Color Combination & Red/Green/Orange
\end{tabular}


feeling by the diagonal or vertical lines using inclined or void ceiling type that produces the vertical open feeling. The artificial light is much effective than the natural light. The tracking type lighting equipment is the element expressed with straight line and the straight lie or parallel types of furniture arrangement also same design element. That is, the straight line element of the horizontal, vertical or diagonal lines has the directional properties and is the important element to produce 'unique' emotional space. The floor color can be used the green, blue, or brown and the furniture and accessory is made with red, green or orange. In case of ceiling, the material and the type are special but not distinguished color should be used with the achromatic color. The color combination of emphasis by the diverse chromatic colors of cold colors and warm colors makes the space distinguished and give the individuality.

(6) The most important assessment variable for the space of sensibility 'congenial' is the form. Particularly the wall material, form and color should be considered. The symmetric, stable and simple space should be build by the 3-surface wall type and flat type ceiling rather than wide space. The partially dispersed type of window having less than half of the wall area, the stand type lighting equipment, which allows free arrangement, the decorative effect protruded in the ceiling by the pendent or track type of lighting equipment, the freely dispersed furniture arrangement as the spot-like design element and can be applied to make freewheeling and rhythmical effects. Those are to express the flexible space by harmonizing natural and artificial lights rather than dramatic effects by the excessive natural light. Green, red or brown are to be used as wall color, and the diverse color should be used for furniture and accessory colors than the wall color and made by complex color combination by the achromatic colors such as warm

Table 15. The Interior Design Application Elements of Sensibility 'Congenial'

\begin{tabular}{ccc}
\hline Variable & Design Attributes & Application Element \\
\hline \multirow{4}{*}{ Form } & Wall Construction & 3 Surfaces \\
& Ceiling Form & Flat \\
& Window Area & Less than $1 / 2$ \\
& Window Arrangement & Dispersed \\
& Lighting Fixture Form & Stand/Pendent \\
& Furniture Arrangement & Dispersed \\
\hline \multirow{3}{*}{ Color } & Wall & Green/Red/Brown \\
& Furniture \& Accessory & Yellow/Orange/Black/ \\
& Color Combination & Brown/Blue/Green \\
\hline Material & Wall & Complex \\
\hline
\end{tabular}

colors and black rather than cold colors. For wall material, the brick having small size and natural texture or the fabric that produces the atypical, soft and free lines should be used.

(7) The most important assessment variable for the space of sensibility 'sensuous' is the color. Particularly the wall color, material, and form should be considered. For the wall color, the cold colors and brown are to be used excluding achromatic colors, and the furniture and accessory should be designed with color combination of accent using diverse colors excluding the achromatic colors. The dynamic space feeling should be produced by the inclined or void ceiling, and by the artificial light without window. The direction of the light should be expressed as linear element by the pendent or track lighting exposed in the ceiling, and the free space arrangement should be made by the dispersed or straight-line furniture arrangement. For the wall material, the element of the natural and rough texture can be applied using woods, natural rock, brick, steel, exposed concrete, etc.

Table 16. The Interior Design Application Elements of Sensibility 'Sensuous'

\begin{tabular}{ccc}
\hline Variable & Design Attributes & Application Element \\
\hline \multirow{3}{*}{ Color } & Wall & Green/blue/Brown \\
& Furniture \& Accessory & Red/Green/Orange/White/Brown \\
& Color Combination & Accent \\
\hline \multirow{4}{*}{ Form } & Ceiling Form & Slope/Void \\
& Window Area & Nothing \\
& Lighting Fixture Form & Pendent/Track \\
& Furniture Arrangement & Dispersed/Straight \\
\hline Material & Wall & Wood $>$ Natural Stone $>$ Brick \\
\hline
\end{tabular}

(8) The most important assessment variable for the space of sensibility 'gorgeous' is the color. For the floor color, white should be used as dominant color, and red, blue, and green can be used as auxiliary color. For the wall color, blue, green or red can be used, and for the furniture and accessory color, the color combination of accent may be used around the red, green, blue, grey and the orange. The diagonal element of the incline ceiling can be applied as supplement.

Table 17. The Interior Design Application Elements of Sensibility 'Gorgeous'

\begin{tabular}{ccc}
\hline Variable & Design Attributes & Application Element \\
\hline \multirow{3}{*}{ Color } & Floor & White+Red/blue/Black \\
& Wall & Blue/Green/Red \\
& Furniture \& Accessory & Red/Green/Blue/Grey/Orange \\
& Color Combination & Accent \\
\hline Form & Ceiling Form & Slope \\
\hline
\end{tabular}




\section{Conclusions}

The residential interior space in future should be useroriented space environment to maximize the satisfaction of the users focused on the role of sensibility and the effects of sensibility on the users. The users, who consume the space, form the meaning of the space through the consumption of psychological and mental values of the individual, and particularly the residential space should be reborn as the space having identity of the sensibility by realizing user's unique sensibility and lifestyle. The residential interior space design alternative reflected with the user's sensibility through the much systematic sensibility engineering approach was suggested. To graft the uncertain and ambiguous qualitative sensibility data with the interior design elements, the linear regression model in the quantification theory was used. The sustainable measure to be applied to the residential interior design responding to the user's sensibility was suggested specifically by extracting interior design attributes by the sensibility factor through the diverse approach and analysis methods.

In this study, to overcome the limitation of existing approaches in the sensibility study, the research was performed through the much systematic sensibility engineering approach method by quantifying the qualitative data. Since the residential interior images reflecting with recent trends were limited to the living room during that process, there is the limit in interpreting and expanding them to the other residential spaces. In addition, since the residential images were limited to 42 images due to the limitation of the research period, there was the limit in identifying the influences of the much diverse interior design elements. Therefore, in the future study, to generalize the research results, the sensibility assessment should be made much diverse age groups and users by diverse regions, and if there is difference by the other variable should be verified. In addition, the author expects that the results of this study shall be complimented by specifying and extracting interior design application elements by the much diverse sensibility factors, interior design, and more segmented assessment items.

\section{REFERENCES}

1. Junychi, N. (1994). Secrets of Colors. Seoul: BoGoSa.

2. Lefebvre, H. (1991). The Production of Space. Blackwel. pp. 51.

3. Nagamachi, M. (1995). Kansei Engineering: a new ergonomic consumer-oriented technology for product development. International Journal of Industrial Ergonomic, 15, 3-11.

4. Neung, J. (1993). Representation of Textures for Designers. Seoul: MyungJi Publisher.

5. Noh, H. (2005). Theory and Practice of Multivariate Analysis using Excel \& SPSS. Seoul: HyungSul Publisher.

6. Park, H. (2001). Preference of Interior Design according to Life Style. Unpublished doctoral dissertation, Yonsei University, Seoul.

7. Park, J. (2013). The Study of Interior Design Application Elements according to the Sensibility Evaluation of Housing Interior Space. Unpublished doctoral dissertation, Yonsei University, Seoul.

8. Park, J., Yoon, C. \& Park, E. (2012). A Study on the Correlation between Sensibility and Housing Interior design Attributes. A Journal of Korean Architectural Institute, 28(8), 73-82.

9. Saito A., Munemoto J. \& Matsushita D. (2005). Study on Inference of Combination Rules of Form Elements by Sensibility evaluation Employing Rough Set Theory: a case of Sanneizaka preservation district for groups of historic buildings. Journal of Architectural Institute of Japan, 594, 85-91.

10. Satoru, F. (1994). The Psychology of Beauty \& Molding. Seoul: JoHyungSa.

11. Schütte, S., Eklund, J., Axelsson, J. \& Nagamachi, M. (2004). Concept, Methods and tools in Kansei Engineering. Theoretical Issues in Ergonomics Science, 5(3), 214-231.

12. Solso, R. (1996). Cognition and the visual Arts. Cambridge: The MIT Press.

13. Song, J. (2009) SPSS/AMOS Statistical Analysis Method. Gyeonggi: 21Centuries.

14. Takemura M., Matsumoto Y. \& Naka R. (2008). The Sensibility evaluation for Extraction of Design Guideline of Meeting Room in Office. Journal of Architectural Planning, 277-278.

15. Yu, E. (2008). A Study on the Image words Evaluation of Space Design. A Journal of Korean Architectural Institute, 24(12), 123-130.

접수일 $(2014.4 .25)$

수정일(1차: 2014. 6. 6)

게재확정일자(2014. 6. 17) 